Editorial

\title{
Rural restructuring in China
}

\section{Keywords:}

Rural restructuring

Urban-rural development

Disciplinary interaction

International Geographical Congress

China

\begin{abstract}
A B S T R A C T
This multidisciplinary special issue examines the contemporary rural restructuring in China, focusing on spatial restructuring, economic restructuring and social restructuring and the key challenges for rural areas, whether at local, regional, national or international level. The contributions to this special issue provide conceptual-theoretical and empirical takes on rural restructuring in China. However, the volatility and complexity of rural restructuring in China will present ongoing challenges for further research on the restructuring of rural China. In view of this, this themed edition makes a compelling call for more systematic research of rural restructuring based on extensive disciplinary interaction. This special issue is published to coincide with the 33rd International Geographical Congress (IGC) of IGU in Beijing.
\end{abstract}

(C) 2016 Elsevier Ltd. All rights reserved.

\section{Introduction}

Rural restructuring was defined by Woods (2009a) as "the reshaping of social and economic structures in rural areas during the late twentieth century and early twenty-first century produced by various, interconnected processes of change including the declining economic significance of agriculture, the rise of the service sector, urban to rural migration, and so on". Actually, rural China has experienced a rapid and far-reaching reshaping of social and economic structures since the late twentieth century, especially the beginning of China's economic reforms in 1978. As China evolves into a majority urban country, these processes present a number of challenges to the rural areas which have been confronted with significant changes and subsequent restructuring of rural socio-economic morphology and territorial spatial patterns, including changes in demographic structures, employment opportunities, community organization, lifestyles and standards of living, accessibility, rural culture as well as the restructuring of rural industries and rural production, living and ecological spaces (Woods, 2005; Long et al., 2012; Long, 2014; Long and Liu, 2015).

There are significant spatial variations in the experience and impact of economic and social restructuring in rural China ( $\mathrm{Li}$ et al., 2015). Whilst rural income levels have improved in many regions, especially those close to large urban centers, urban-rural inequalities in income and uncoordinated urban-rural development have increased in more developed regions (Long et al., 2011; Liu et al., 2013). Furthermore, by the end of 2014, there were still 14 contiguous poverty-stricken areas, 592 national poverty counties, 128 thousand impoverished villages, 29.49 million poor families, and 70.17 million rural poor in China (Long et al., 2016a). Usually, most contiguous poverty-stricken areas lie in revolutionary base areas, minority areas, remote and border areas with bad physical conditions and weak socio-economic foundation, which determines that the task of poverty reduction is arduous in these areas (Liu et al., 2016a; Long et al., 2016a). Recently, with the rapid advance of urbanization, the negative effects of urban-rural and inter-regional development gap are increasingly obvious and have attracted more attention (Long et al., 2016a). Yet rural restructuring in China continues to be strongly shaped by national macroeconomic development strategies, a critical analysis of which is needed so as to gain a new recognition of the centrality of rural restructuring to the development of the national economy (Long and Woods, 2011; Long et al., 2012; Long and Liu, 2015).

Meanwhile, rural China is increasingly integrated into global social and economic networks (Long and Woods, 2011; Woods, 2012). Increased political, economic and cultural openness has exposed rural localities in China to globalization processes - such as global trade and economic competition, international migration, and cultural assimilation - that are already contributing to the reconstitution of rural places elsewhere (Woods, 2007, 2012). As such, the problems associated with rural restructuring in China may in part be addressed by drawing on experiences and achievements from other countries, which may have experienced similar developmental stages as part of their trajectory of rural progression (Long and Woods, 2011; Long and Liu, 2015).

However, the relevant literature on rural restructuring in China is scarce and this exposes a number of theoretical, methodological and practical difficulties (Long, 2012; Liu et al., 2016b). In order to address this research gap, this special issue aims to advance our understanding of the contemporary rural restructuring in China, focusing on spatial restructuring, economic restructuring and social restructuring, and the key challenges for rural areas. The contributions in this special issue seek to offer novel multi-disciplinary contributions that provide important, original and creative solutions to the analysis, monitoring and measuring of rural restructuring in China, whether at local, regional, national or international level. 
The next section provides a brief description of each of the twenty five papers included in this special issue.

\section{Contents of the special issue}

Aiming at the increasing trend emphasizing the role of regional resources in formulating rural development policy and restructuring rural areas, Long et al. analyze the rural restructuring in China affected by the allocation and management of critical resources including human resource, land resource and capital, by establishing a theoretical framework of "elements-structure-function" of rural territorial system. The paper by Long et al. argues that rural restructuring is a process of optimizing the allocation and management of the material and non-material elements affecting the development of rural areas and accomplishing the structure optimization and the function maximization of rural development system, and it is necessary to restructure the contours of state intervention in rural societies and economies and allocate and manage the critical resources affecting rural development, from the perspectives of integrating urban and rural resources, improving the efficiency of resources utilization, and fully understanding the influences of globalization on rural restructuring in China. The paper also addresses the problems and challenges for the future development of rural China, including deagriculturalization, non-grain preference and the abandonment of farmland use together with the derelict and idle rural housing land, the weakening mainstream of rural development, the unfair urban-rural allocation of capital and its structural imbalance. Aiming at how to resolve the problems and adapt to the challenges, Long et al. point out that it is pivotal to restructure the rural development space, rural industry, and rural social organization and management mainstream, which form the three aspects of rural restructuring, i.e., spatial restructuring, economic restructuring and social restructuring. In general, the remaining twenty four papers included in this special issue may be individually set in relation to the abovementioned three aspects of rural restructuring.

\subsection{Spatial restructuring}

Due to the constraints from the maintained urban-rural dualism of land ownership and household registration as well as unstable rural development institution and mechanism and backward rural infrastructures (Long et al., 2010), the scattered distribution and hollowing of rural settlements, the fragmentation of farmland and the disordered arrangement of township and village enterprises in its early stage make the implementation of new-type urbanization and agricultural modernization strategies in China lack of a major hand grip and spatial supporting platform, which greatly affects the advancement of urban-rural integration development. On the one hand, production elements would be depleted in the flow process due to chaos production space and the cost of economic development would be increased. On the other hand, it is difficult to put the optimal allocation of rural public infrastructure and socialization services into implementation. Hence, it is necessary to restructure rural production, living and ecological spaces, so as to establish a new platform for building new countryside and realizing urban-rural integration development in China (Long, 2014). Rural spatial restructuring is an optimization and adjustment even utterly change process of rural production, living and ecological spaces accompanied by the reshaping of socioeconomic structure in rural areas owing to an integrated result of endogenous development need and exogenous driving forces of rural development, under the pressure of rapid industrialization and urbanization, and it is also an integrated approach aiming at optimizing urban-rural space organization and promoting coordinated urban-rural development (Long, 2014). Eight papers in this special issue address the spatial aspects of rural restructuring in China.

Using the methods of nearest neighbor distance analysis and geographical detector analysis, Yang et al. conclude the spatial distribution of rural settlements in China with significant regional differences, i.e., denser in the southeastern regions compared to the northwestern regions, high density and mainly random and disperse in plains, and low density and mainly clustered in regions such as cold alpine areas and desert fringes. The detected influential factors contributing to these spatial distributions include traditions and the economy, average distance to main roadway, agricultural machinery, per capita grain production, per capita arable land, population density, elevation, precipitation, etc. Accordingly, multiple distribution patterns are developed to restructure the rural spaces in different geographical areas, such as radially imbalanced distribution mode, multicore central land distribution mode, corridor balanced and imbalanced distribution mode, and radially balanced, central land distribution mode.

Liu et al. investigate the spatial patterns, temporal processes and driving mechanisms of urban-rural land use transformation based on the case study of Xuanhua district of Hebei province, and argue that industrialization and urbanization are the basic driving factors of urban-rural land use transformation, and local, regional and national socio-economic transformation deeply and widely affect its development. The paper by Liu et al. then highlights that the regional development should implement correct urban-rural transformation strategy and plan according to its location and nature resources conditions, and obey the spatial laws of urban-rural transformation for improving the efficiency of land use and promoting urban-rural integration.

Yao and Xie examine rural spatial restructuring in an ecologically fragile mountainous area of southern China at a villagetownship level based on a set of methods concerning landscape security pattern construction as well as a model of rural residential land expansion using an ant colony optimization algorithm and scenario simulation, which were proved to be a useful technical toolkit supporting rural spatial restructuring in the ecologically fragile mountainous areas of southern China. Yao and Xie argue that it is necessary to recognize and better explore the multiple functions of the countryside, and the government's scientific planning and appropriate control of self-renewal processes of rural space can make more economical use of land, and can guarantee the provision of public goods such as ecological welfare and food security.

Land consolidation is a spatial problem-solving land management instrument and is also regarded as an indispensable way of spatial restructuring in rural China (Long, 2014). It is worth mentioning that rural construction land consolidation locking up unused rural housing land in 'hollowed villages' accelerates the restructuring in rural China fueled by 'increasing vs. decreasing balance' land-use policy, which seeks to balance increases in urban construction land with a reduction in rural construction land (Long et al., 2012). It is an innovative approach to coordinating the outmigration of a rural population and the increase in rural housing land for China in the context of concerns over urban development and food security, thereby protecting farmland and ensuring food security, adding to urban construction land quotas, and improving the rural habitat environment in China. In the remaining parts of this rural restructuring type we provide brief details on each of the five articles concerning rural spatial restructuring via land consolidation.

Liu et al. investigate the drivers of land coverage under the program of community-based agricultural land consolidation aiming at restructuring the agricultural sector by pooling fragmented land and leasing it as consolidated plots or employing labors to 
farm the land, with a particular interest in the role of local elites and village characteristics. The paper by Fang et al. analyzes the means and ends of the practices and villagers' attitudes and behaviours in response to rural construction land consolidation based on a comparison of a failed case and a successful case in Changchun city, northeast China, and suggests that rural construction land consolidation should follow a trial and error approach and villagers must have real opportunities to take part in the decision-making that will influence their futures. Aiming at the "land bill system" concerning rural construction land consolidation innovated by Chongqing governments, the paper by Yep and Forrest provides an account of the genesis, implementation and evaluation of this new scheme, and points out that this institutional innovation seems to provide a win-win situation for all stakeholders, but peasants may suffer in the long run and the impact on rural governance may also be damaging. Wang et al. analyze the elements, mechanisms and operation of a peasant household symbiotic system in the process of rural settlement restructuring based on the case study of Fengsi village in Chongqing, and develop the spatial pattern by establishing a symbiotic relationship among which resources, benefits and responsibility for environmental construction are shared. The paper by Lo et al. examines poverty alleviation resettlement, one of China's key poverty reduction initiatives, from the perspective of spatial restructuring through a household survey conducted in Shanxi and Shaanxi provinces, and describe the significant challenges remain to be addressed for shortdistance resettlement and long-distance resettlement, including establishing two-way communication between villagers and the government about resettlement plans and providing better financial support for the resettlers, safeguards for the livelihoods of non-movers, and post-resettlement support programmes to help resettlers adjust to their new environments.

\subsection{Economic restructuring}

Since industrial development imposes great effects on widening farmers' employment channel, transforming land use mode, enhancing rural economic strength and self-developing ability, economic restructuring based on industrial reshaping is becoming increasingly important in rural restructuring (Long et al., 2016b). The improvement of rural economic strength may ensure the implementation of rural spatial restructuring and social restructuring. Hence, restructuring the rural economic engine with the core of industrial cultivation is one of the fundamental issues of rural restructuring. However, to cope with the new trend of economic operation and meet the needs of rural-urban development transformation, rural economic restructuring should be established on the deep analysis of regional advantages and external market demands (Long et al., 2016b). Eight papers in this special issue deal with the efforts to restructure the rural economic system of China.

Based on Hirschman's 'exit-voice' theory, Li et al. investigate the way in which local stakeholders respond to the processes of rural decline based on the case studies of Xiaoguan village in China and Åre in Sweden, and reveal the effectiveness of bottom-up revitalization initiatives in combating rural decline, by showing how local stakeholders' strong "voices" in these places held people and groups together, encouraging them to work together with shared values and attitude. The paper by $\mathrm{Li}$ et al. indicates that strong leadership demonstrated either by local committees or in stakeholders' self-organized actions played an important role in carrying out revitalisation initiatives, and emphasizes the need for bottom-up initiatives to align with government policy and regional development plans.

Aiming at the booming of Taobao villages which specialize in ecommerce and are changing the pattern of the rural economy as well as the social foundation of rural daily life throughout China, the paper by Lin et al. explores how everyday life in rural China has changed in response to the development of the network economy. The case study of Junpu village in Guangdong province shows that the development of e-commerce and network technology has changed the common values held towards rural life, the affection felt for the village, and the pace of life of local people. However, the intrusion of this new force of network economy has been resisted by local cultural structures such as family, clans, religion, and gender dynamics, leading to an unprecedented hybrid rurality.

Under the background of rural transformation development, vast amounts of land have been abandoned due to labor loss, especially in mountainous areas. The paper by Zhang et al. examines how two main farmland parcel attributes, farmland-to-housing distance and land quality, by affecting farming costs and benefits, and thereby profits, determine farmland abandonment, by establishing a semi-empirical crop profit model based on output benefits and input costs derived from household survey data from mountainous Wulong county, Chongqing. The observed occurrence of land abandonment in relation to farmland-to-housing distance and land quality is concordant with the model's predictions, verifying the underlying hypothesis that land will be abandoned when the farmland-to-housing distance exceeds the "zero profit distance".

Using a qualitative comparative analysis approach, Qin and Liao conduct a systematic review and meta-analysis of recent case studies of labor out-migration and agricultural change in rural China, and reveal a general contextual pattern of migration impacts on agriculture. The results show that migration-induced agricultural change was mainly conditional upon the specific conjunctural configuration of a rural community's economic development level or geographical locality, its land resources and dependence on agriculture, and whether the period under investigation was postagricultural tax abolition. Overall, this meta-study provides a big picture of the complex migration-agriculture relationships in rural China, which is often missed in smaller-scale case studies.

Qian et al. explore the key impacts of migration on agricultural restructuring in Jiangxi province by considering household farm activities choice and crop acreage adjustment behaviour. The results show that, amid China's unique institutional background, the farmers left behind will be more likely to turn to less laborintensive subsistence grain production instead of more capitalintensive livestock cultivation, or to even abandon their farmland. On the one hand, a serious shortage in agricultural labor inputs has resulted in the decrease in both grain and cash crop acreage and a substantial decline in agricultural land utilization efficiency. On the other hand, the absence of land transfer markets and imperfect land property rights institutional system will make the farmland abandoned. However, return migrants can provide both financial and human capitals to promote more specialized agricultural production in the process of China's agriculture modernization. The paper also proposes some suggestions on China's agricultural restructuring in the future.

The paper by Zhang et al. quantitatively analyzes the impact of labor and capital productivity on wheat production in Shandong and Henan provinces, two leading provinces for grain production and also have the highest population in China, and the consequent effects on exported and imported wheat volumes in other provinces, using the Enormous Regional Model. The results show that the magnitude of change generated by the increase in labor productivity is larger than that generated by the increase in capital productivity. This study also reveals that regional competitive industry can easily shape absolute competition superiority, which consequently exerts a large impact on the homogeneity of products. Rural China should form stable, sustainable, and specialized 
agricultural production arranged by geographic areas, which would not only guarantee China's food security, but also improve the nation's competitive capacity in the international market.

By combining the traditional three-stage Malmquist productivity index (MPI) with the Bootstrap-Malmquist productivity index (Bootstrap-MPI), Song et al. measure the changes of the total factor productivity (TFP) of crop production in 31 provinces/autonomous regions in China from 1999 to 2008. The results show that, on the whole, the traditional MPI model underestimates the TFP of China's crop production and its components, the technical change index and technical efficiency change index, and the TFP of China's crop production had an annual average increase rate of $6.1 \%$ during 1999-2008, with obvious fluctuations in different time periods. The paper by Song et al. also indicates that the TFP of crop production in China began to decrease since the implementation of the protective policy for grain purchase prices in the 1990s; however, the TFP increased dramatically after the rural tax reform during 2002-2003.

The paper by Tian et al. examines rural livelihoods within the broader development context in China, by elaborating the various components in the agricultural and industrial sectors that contribute to the two-sector dynamics in the Chinese urbanization context and illustrating the microeconomic foundations of the twosector dynamics and the interactive processes underlying the livelihoods of rural households amid urbanization, i.e., how individual household characteristics interact with local and macro processes to shape their livelihood options, choices, and outcomes. This paper reflects on how development, migration and land policies may synergistically foster healthy rural-urban development dynamics to lift system-level constraints for the majority of rural households and facilitate rural households' building robust livelihoods via different paths, ensuring urbanization to proceed in a way that best benefits all rural households.

\subsection{Social restructuring}

With the advancing of globalization, urbanization and industrialization, the foundation maintaining Chinese traditional rural society consists of agricultural civilization, village culture and family clanship has been broken (Long et al., 2016b). Accompanying with a growing number of prime rural labors flow into cities, serious brain drain arises in rural area. Rural human resource tends to be low level, and the mainstream of rural development has been weakened continuously. Meanwhile, the unfairness and structural imbalance of public goods and capital allocation owing to rural-urban dual system cause rural development resources further occupied by the urban, and rural self-development ability further weakened. Generally, traditional village community has been disassembled, and local rural development is facing some serious problems, such as outflow of rural population, the downfall of organization system and distortion of value system. There is an urgent need to reconstruct rural social structure emphasizing particularly on the organization system and rural management mainstream (Long et al., 2016b). Eight papers in this special issue address the social aspects of rural restructuring in China.

Drawing on the analytical framework of historical institutionalism, the paper by Kan treats the Chinese village as a historical entity emerging from socialist collectivisation and examines how the socialist institutions of collective property and redistributive mechanisms have continued to persist in the reform-era village. Kan argues that an examination of the resilience of the village collective in urbanising China not only sheds light on the structures and processes of power that contribute to its continued vitality, but also generates insight into how the "village" or the "rural" should be conceived of in the context of rapid administrative, economic and territorial transformation. The editor Professor Michael Woods made special comments for this paper and thought that Kan's paper not only documents a key phenomenon in contemporary China, but draws attention to rurality in the city, which will be an important emerging area of rural research.

Rao and Ye explore the historical transformation of the rural education system and the mapping of rural schools in ancient, modern and contemporary China to explain the problems of the Rural School Mapping Adjustment policy. Although China has attempted to reduce the disparity between cities and the countryside by increasing the public financial investment in rural basic education after achieving a universal basic education, the case study in a village in North China demonstrates that the urban-oriented school mapping adjustment takes a toll on the rural area and exacerbates the problem of educational inequality, which actually increases the gap between urban and rural areas and between the rich and the poor. The paper by Rao and Ye suggests that the Chinese government should strive to develop a rural-oriented and rights-based rural basic education system and school mapping adjustment.

The paper by He et al. adopts a method that combines economics and geography, and conducts dynamic monitoring and evaluations of the efficiency of rural public goods investments in specific mountainous areas based on long-term data from tracking surveys. The results show that rural public infrastructure and public services in mountainous areas are increasingly valued and have received considerable support in terms of government financial contributions, the burden of investments at the village level continues to decrease, the technical efficiency of rural public investments has risen to relatively high levels, and scale efficiency plays a crucial role in public investment efficiency. The efficiency of rural public investments in mountainous areas is mainly influenced by physical terrain, location and transportation. However, villagelevel democratic systems and village governance have gradually become key factors that influence public investment efficiency. He et al. also offer policy recommendations for increasing the efficiency of public fund usage and promoting rural restructuring.

The resilience and adaptability of rural communities to environmental uncertainties events is one of the major areas that present key challenges for rural areas in the early 21st century (Woods, 2012). Jiang et al. analyze the adaptive capacity incorporating a variety of geological disaster susceptibilities in prefecture-level cities in the mountainous rural Yunnan province by using socioeconomic data and geological disaster data. The results show that economic conditions were the most important factor that affects the adaptive capacity, and cities with high geological disaster susceptibility but low adaptive capacity require more attentions to prepare for geological disasters and improve their adaptive capacity. The paper by Jiang et al. indicates that evaluating the adaptive capacity needs taking both the socio-economic background and natural disaster conditions into account, and it is more realistic to determine the local adaptive capacity and then implement targeted measures to improve the adaptive capacity.

Aiming at the situation that traditional dwellings in rural areas are gradually disappearing as part of the residents' long-term daily practices, the paper by Wang et al. discusses the changes in the traditional cave dwelling called "sunken courtyard" (known as "di keng yuan" in Mandarin) in Shanxian county, Henan province, and explores the reasons behind these changes, based on the literature and preliminary investigation as well as a formal interview. The results indicate the causes of the changes in terms of decoration, custom, family structure and policy. Wang et al. argue that rural land use policy, the limitations of the sunken courtyard itself, the change in residents' ideas and the lack of proper management are the major reasons for this heritage change phenomenon, and proffer a method regarding the protection of traditional dwellings 
to attract attention to the disappearing dwellings and to provide a scientific planning method for them.

Zacharias and Lei examine the community relations among villagers, artists and students in Xiaozhou, a peri-urban village in south China is regenerating by developing its own productive economy, in the context of threats to the village's long-term survival, based on structured and semi-structured questionnaires and indepth interviews with artists. The results show that artists and villagers have gradually increased their interactions, with villagers' participating in the artistic life of the community and artists' establishing longer-term relations with their hosts. However, the arrival of art students has altered the economic foundation of these relationships, threatening the survival of the art community as well as much of the historic building fabric.

The paper by $\mathrm{Wu}$ et al. demonstrates the multiple dualities in the social-spatial dimension of villages in semi-urbanized suburbs of China's large cities have emerged during China's rapid urbanization. The results show that these dual characteristics are derived from the institutional separation of urban and rural entitlements (e.g., hukou, welfare, land property ownership etc.), and these distinctions are then projected into social capital differentiation, such as the division between the strong and weak ties of local community residents. Consequentially, the dualities are embodied in the residential space segregation between established residents and rural migrants that is divided into Houses in Single-Family Occupancy and Houses in Multiple-Family Occupancy.

Chen et al. use multi-parameter income distribution function and decoupling theory to investigate rural poverty in China, focusing on how demographic structures and economic development have been restructuring the incidence of rural poverty. The results show that the income inequality of the impoverished population in rural areas has gotten worse, and the positive impacts of economic growth on rural poverty alleviation have disappeared in most places. The paper by Chen et al. argues that economic growth cannot solve the problem of rural poverty, and the increasingly serious aging of the population has become the key influencing factor of poverty incidence in most rural areas.

\section{Concluding comments}

This special issue aims at contributing to the new framework of rural studies based on five challenging areas including the sustainable use of resources, the resilience of rural communities to environmental uncertainties, challenges and impacts arising from the intensification and reconfiguration of global mobility patterns on rural space, critical analysis of the political economies of new strategies for rural economic development, and redrawing of the contours of state intervention in rural societies and economies (Woods, 2012). This special issue of Journal of Rural Studies has succeeded in compiling theoretical and empirical studies to highlight rural restructuring in China. The papers make important conceptual-theoretical and empirical contributions to the growing literature on rural restructuring in China. Meanwhile, we should bear in mind that the volatility and complexity of rural restructuring in China, doomed by the rampant urban-rural transformation and the special 'dual-track' structure of urban-rural development, will present ongoing challenges for further research on the restructuring of rural China, which also needs extensive disciplinary interaction (Woods, 2009b).

This special issue is published to mark the 33rd International Geographical Congress (IGC) of IGU, held in Beijing. We hope that this special issue will help to better understand and to capture the character of rural restructuring in China, and to promote further research interests and activities enabling sustainable urban-rural transformation and rural development in China.

\section{Acknowledgements}

We would like to thank all of the contributors to this special issue for their hard work and commitment in producing this volume. On behalf of all contributors, we would like to give our sincere thanks to the editor of Journal of Rural Studies, Professor Michael Woods, for his always present support in this special issue and to the reviewers for their constructive engagement with the manuscripts. For her valuable editorial support we are indebted to Clare Rajkumar. The work on this special issue was supported by the National Natural Science Foundation of China (Grant Nos. 41130748 and 41171149) and the National Key Technology R\&D Program of China (Grant No. 2014BAL01B05).

\section{References}

Li, Y.R., Long, H.L., Liu, Y.S., 2015. Spatio-temporal pattern of China's rural development: a rurality index perspective. J. Rural Stud. 38, 12-26.

Liu, Y.S., Long, H.L., Chen, Y.F., Wang J.Y Li, Y.R., Li, Y.H., Yang YY, Zhou, Y., 2016b. Progress of research on urban-rural transformation and rural development in China in the past decade and future prospects. J. Geogr. Sci. 26 (8), 1117-1132.

Liu, Y.S., Lu, S.S., Chen, Y.F., 2013. Spatio-temporal change of urban-rural equalized development patterns in China and its driving factors. J. Rural Stud. 32, 320-330.

Liu, Y.S., Zhou, Y., Liu, J.L., 2016a. Regional differentiation characteristics of rural poverty and targeted poverty alleviation strategy in China. Bull. Chin. Acad. Sci. 31 (3), 269-278 (in Chinese).

Long, H.L., 2012. Land Use and Rural Transformation Development in China. Science Press, Beijing (in Chinese).

Long, H.L., 2014. Land consolidation: an indispensable way of spatial restructuring in rural China. J. Geogr. Sci. 24 (2), 211-225.

Long, H.L., Li, Y.R., Liu, Y.S., Woods, M., Zou, J., 2012. Accelerated restructuring in rural China fueled by "increasing vs. decreasing balance" land-use policy for dealing with hollowed villages. Land Use Policy 29 (1), 11-22.

Long, H.L., Liu, Y.S., 2015. A brief background to Rural Restructuring in China: a forthcoming special issue of Journal of Rural Studies. J. Geogr. Sci. 25 (10), 1279-1280.

Long, H.L., Liu, Y.S., Li, X.B., Chen, Y.F., 2010. Building new countryside in China: a geographical perspective. Land Use Policy 27 (2), 457-470.

Long, H.L., Tu, S.S., Ge, D.Z., 2016a. Effects of new-type urbanization on poverty alleviation and development and corresponding countermeasures. Bull. Chin. Acad. Sci. 31 (3), 309-319 (in Chinese).

Long, H.L., Tu, S.S., Ge, D.Z., Li, T.T., Liu, Y.S., 2016b. The allocation and management of critical resources in rural China under restructuring: problems and prospects. J. Rural Stud. 47, 6-26.

Long, H.L., Woods, M., 2011. Rural restructuring under globalization in eastern coastal China: what can be learned from Wales? J. Rural Community Dev. 6 (1), 70-94.

Long, H.L., Zou, J., Pykett, J., Li, Y.R., 2011. Analysis of rural transformation development in China since the turn of the new millennium. Appl. Geogr. 31 (3), 1094-1105.

Woods, M., 2005. Rural Geography: Processes, Responses and Experiences in Rural Restructuring. Sage, London.

Woods, M., 2007. Engaging the global countryside: globalization, hybridity and the reconstitution of rural place. Prog. Hum. Geogr. 31, 485-507.

Woods, M., 2009a. Rural geography. In: Kitchin, R., Thrift, N. (Eds.), International Encyclopedia of Human Geography, vol. 9. Elsevier, Oxford, pp. 429-441.

Woods, M., 2009b. Rural geography: blurring boundaries and making connections. Prog. Hum. Geogr. 33 (6), 849-858.

Woods, M., 2012. New directions in rural studies? J. Rural Stud. 28 (1), 1-4.

Hualou Long*, Yansui Liu Institute of Geographic Sciences and Natural Resources Research, Chinese Academy of Sciences, 11A Datun Road, Chaoyang District, Beijing 100101, China

* Corresponding author.

E-mail addresses: longhl@igsnrr.ac.cn (H. Long), liuys@igsnrr.ac.cn

(Y. Liu).

Available online 4 August 2016 